Portland State University

PDXScholar

Psychology Faculty Publications and

Presentations

Psychology

$10-2020$

\title{
A Dyadic Examination of Drinking Behaviors within Military-Connected Couples
}

James D. Lee

Portland State University, jdl6@pdx.edu

AnnaMarie Sophia O'Neill

Portland State University, oneillannamarie7@gmail.com

Emily Catherine Denning

Portland State University, e.c.denning@gmail.com

Cynthia Mohr

Portland State University, cynthia.mohr@pdx.edu

Leslie Hammer

Portland State University, hammerl@pdx.edu

Follow this and additional works at: https://pdxscholar.library.pdx.edu/psy_fac

Part of the Applied Behavior Analysis Commons, and the Counseling Psychology Commons Let us know how access to this document benefits you.

Citation Details

Published as: Lee, J. D., O’Neill, A. S., Denning, E. C., Mohr, C. D., \& Hammer, L. B. (2020). A dyadic examination of drinking behaviors within military-connected couples. Military Behavioral Health, 1-14.

This Post-Print is brought to you for free and open access. It has been accepted for inclusion in Psychology Faculty Publications and Presentations by an authorized administrator of PDXScholar. Please contact us if we can make this document more accessible: pdxscholar@pdx.edu. 


\title{
A Dyadic Examination of Drinking Behaviors within Military-Connected Couples
}

\author{
James D. Lee, AnnaMarie S. O’Neill, Emily C. Denning, Cynthia D. Mohr \\ Portland State University \\ Leslie B. Hammer \\ Portland State University \\ Oregon Health \& Science University
}

The U.S. Army Medical Research Acquisition Activity, 820 Chandler Street, Fort Detrick MD 21702-5014 is the awarding and administering acquisition office. This work was supported by the Office of the Assistant Secretary of Defense for Health Affairs, through the USAMRMC Broad Agency Announcement under Award W81XWH-13-2-0020. Opinions, interpretations, conclusions and recommendations are those of the author and are not necessarily endorsed by the Department of Defense. Results of a draft of the article were presented at an academic conference in the form of a poster presentation (Poster presented at the 2018 Society for Personality and Social Psychology Annual Convention Health Pre-conference, Atlanta, GA). Correspondence concerning this article should be addressed to James D. Lee, Department of Psychology, Portland State University, Portland, OR 97201. E-mail: jd16@pdx.edu. 


\section{Abstract}

High rates of alcohol use have been documented within military personnel and spouses. However, scant research has investigated alcohol consumption behaviors in matched couples or nonclinical veteran samples. The manner in which couples influence one another's drinking remains unclear. The current study examined hazardous drinking scores and drinking behaviors in a sample of post-9/11 separated service members (most of whom were veterans) and active duty reservists and their spouse/partners; 260 military-connected couples participated in the Study for Employment Retention of Veterans (SERVe) and were recruited from 35 workplace organizations in the Pacific Northwest. Participants completed baseline and daily surveys on alcohol consumption over the span of 32 days. Among study highlights, Actor-Partner Interdependence Models (APIM) revealed actor effects for psychological distress predicting alcohol use variables. Significant partner effects were also revealed for hazardous drinking (AUDIT) scores predicting subsequent alcohol use, over and above actor (i.e., within-person) effects of those relationships. Higher levels of subsequent drinking frequency and quantity were evident among partners of veterans with higher hazardous drinking scores. Spouses with higher hazardous drinking scores were associated with veteran partners who drank more frequently. Results shed light on how military-connected couples, particularly those engaging in hazardous drinking, uniquely influence one another's alcohol consumption behaviors. Ultimately, findings highlight the importance of including spouses of veterans to elucidate the interplay of drinking behaviors within military-connected couples.

Keywords: Military, Veterans, Military Spouses, Alcohol, Hazardous Drinking, APIM, Psychological Distress 


\section{Introduction}

It has been well-documented that Service Members (SMs) of the U.S. Armed Forces have higher rates of binge drinking and heavy episodic drinking (HED) than their civilian counterparts. Some work estimates that $40 \%$ of married service members report heavy drinking (Bray et al., 2006), which is over twice the rate of married civilians (e.g., 13\%; Paul, Grubaugh, Frueh, Ellis, \& Egede, 2011). This pattern of heavy alcohol use has been observed in active-duty (AD) samples, National Guard/Reserve (NGR) components, and veterans. Combat veterans currently serving in the NGR have also been found to have high levels of hazardous alcohol, such that prevalence rates of heavy weekly drinking, binge drinking (more commonly referred to as HED), and alcohol-related problems were 9.0\%, 53.6\%, and 15.2\%, respectively (Jacobson et al., 2008). Additionally, these rates of alcohol use were even higher among those with combat exposure. With respect to NGR soldiers and spouses, previous work has also found high rates of hazardous drinking, such that $29.2 \%$ of SMs and $10.7 \%$ of spouses met criteria for hazardous alcohol use (Blow et al., 2013), which currently surpasses the rates of their civilian counterparts (e.g., heavy drinking $7.0 \%$ of civilian population, Center for Behavioral Health Statistics and Quality, 2016). While much research has examined alcohol use among AD and NGR populations, recent findings have suggested that separated veterans may be at higher risk for heavy alcohol use. This increased risk could be partly explained by the stressors associated with transitioning from service member to civilian, according to Military Transition Theory (Castro \& Kintzel, 2014). When comparing problematic alcohol behaviors by military status, it was found that separated male soldiers were 50\% more likely to report alcohol problems when compared to AD soldiers (Vest, Homish, Fillo, \& Homish, 2018). Specifically, 16.3\% of AD males and 25\% of males who had separated from the military met criteria for hazardous drinking. Thus, male 
veterans may be at higher risk for alcohol-related problems than $\mathrm{AD}$ populations even after accounting for combat exposure. Similarly, soldiers separated from the military have higher rates of alcohol dependence in comparison to current reserve soldiers (Hoopsick, Fillo, Vest, Homish, \& Homish, 2017). Furthermore, NGR members and veterans had a statistically higher likelihood of alcohol misuse across multiple categories (e.g., heavy episodic drinking, heavy weekly consumption, problem drinking) relative to AD SMs in a longitudinal examination of military factors associated with unhealthy alcohol use (Jacobson et al., 2020). It is possible that these higher rates of drinking could have been due to stressors associated with military separation or as an expression of veterans' newfound autonomy post-military discharge.

Although little work has examined the drinking behaviors of military spouses, a review of available studies of military families provides evidence suggesting that their alcohol abuse has increased since 2001 (Booth et al., 2007). For instance, one SAMHSA study found that military wives were more likely to engage in HED in the past month compared to married women within the general population (31.5\% vs. 22.7\%; Lipari, Forsyth, Bose, Kroutil \& Lane, 2016). Yet, a meta-analysis of military spouse drinking behaviors (Gribble et al., 2018) found insufficient evidence to suggest that military spouses have higher rates of hazardous alcohol use. However, of the studies conducted, most were cross-sectional in nature. Indeed, in their longitudinal study, Blow and colleagues (2013) found that $29.2 \%$ of veterans and $10.7 \%$ of spouses met criteria for hazardous alcohol use; however, the participants were surveyed shortly after deployment reintegration and the findings may be indicative of "post-deployment partying," as opposed to more enduring problematic drinking patterns. Though evidence from the Millennium Cohort Family Study, a comprehensive project examining the effects of military life on families (Trone et al., 2018), revealed that it was not current deployment and communication about deployment 
experiences that was associated increased drinking behaviors among spouses per se. Rather, spouses who were either very stressed by a duty assignment of their SM or troubled by hearing about their SM's deployment experiences reported higher odds of risky and problem drinking.

\section{Drinking partner effects}

Emerging literature has started to investigate couples' drinking from a dyadic perspective, including responses from both members of each couple, and the extent to which romantic partners influence each other's drinking behaviors. Specifically, studies have observed the effects of concordant (i.e., similar) or discordant (different) drinking patterns within couples. Extant research has found that discordant alcohol use is detrimental to relationship functioning among civilian and military-connected couples and increases the likelihood of dissolution (Blow et al., 2013; Foulstone et al., 2016; Homish \& Leonard, 2007). At the same time, partner influence on HED was found to be stable over the course of three years and was applicable to couples within various stages of their romantic relationships (Bartel et al., 2017). In regards to individual actor (within-person) effects, HED remained stable for each partner from baseline to follow-up. Further, significant partner effects in young couples' relationships have revealed that individual HED positively influenced their partner's future HED—surprisingly, this effect was found within the short period of 28 days, indicating the strength of partner influence on drinking behaviors over short time-periods (Mushquash et al., 2013). Contextual factors like days spent with face-to-face contact were associated with couples converging their drinking behaviors regardless of relationship length (Kehayes, Mackinnon, Sherry, Leonard, \& Stewart, 2017), suggesting that individuals may be more likely to adopt the overall drinking patterns of their partners instead of alcohol quantities per se. Together, these studies argue for the importance of 
assessing drinking behaviors of both members of a couple in order to fully understand each individual's drinking patterns.

Whether similar patterns of mutual influence emerge within military and veteran couples is still unclear, as few studies of matched military-connected couples have been conducted. Research is needed to assess the interdependence that occurs within the military couple which subsequently contributes to drinking behaviors in order to fully understand the risks for heavy drinking and to enable more effective prevention efforts. In one of the few military-connected, matched couples studies to date, cross-spouse effects were observed within NGR soldiers and their partners such that male soldiers and their spouses were at increased risk for frequent heavy drinking if the soldier had been exposed to combat even after controlling for age, number of deployments and PostTraumatic Stress Disorder (PTSD; Vest et al., 2018). This study along with other evidence in the civilian and military context point to the importance of examining militaryconnected couples' drinking dyadically and considering psychological distress as a significant contributing factor to heavy drinking. However, there are no studies of which we are aware looking at drinking patterns and associated factors among veterans and spouse/partners dyadically. Our study aims to bridge this gap in the literature on drinking among militaryconnected couples by examining drinking and behaviors that occur within a population of current (i.e., NGR) or former military personnel (i.e., NGR and veterans, respectively) who are working mostly full-time in the civilian workforce.

\section{Distress and drinking in military couples}

Among the motivations to consume alcohol, tension-reduction or drinking to cope with aversive affective experiences is a primary motivator, one that is uniquely associated with the development of hazardous drinking and related problems (e.g., Cooper, Russell, Skinner \& 
Windle, 1992). In considering hazardous drinking in military contexts, there are a multitude of aspects about military culture (e.g., glamorized drinking) and military service and that may lead to such drinking, including elevated psychological distress and mental health issues (Bryant \& Kim, 2013; Choi \& DiNitto, 2011a; Choi \& NiNitto, 2011b). Similarly, self-medication models of alcohol use assert that individuals consume alcohol in an effort to attenuate psychological distress (Khantzian, 2003). Although the majority of service members do not develop psychological distress, veterans of Operation Enduring Freedom/Operation Iraqi Freedom that use Department of Veterans Affairs (VA) services were found to have higher rates of mental health diagnoses, with $25 \%$ receiving a diagnosis, most commonly PTSD (Seal et al., 2007). This finding was affirmed by a meta-analysis conducted by Fulton and colleagues (2015) which found that $23 \%$ of veterans who were also utilizing VA services had PTSD; rates far greater than that of the general population. Additionally, many of these veterans had multiple diagnoses, including anxiety, depression, and substance use disorders (Seal et al., 2007). In our own previous examination of veteran distress and alcohol consumption, we found evidence consistent with these studies, wherein higher levels of psychological distress predicted hazardous alcohol use through heightened levels of drinking-to-cope motivations (Mohr et al., 2018).

Research has also captured mental health issues, as well as hazardous drinking among military spouses. One study examining NGR members and their significant others found a high presence of mental health problems, with $22 \%$ of partners meeting the diagnostic criteria for depression, and $10 \%$ of spouses meeting the diagnostic criteria for suicidal ideation (Gorman, Blow, Ames \& Reed, 2011). In their extensive review of the military family literature from 2006-2017, Hawkins et al. (2018) report on the non-deployment related mental health problems that affect SMs and military spouses while shedding light on the interdependence of their mental 
health. In addition, current and former service members have reported being concerned about their partner's alcohol consumption (Rodriguez, Osilla, Trail, Gore, \& Pederssen, 2017). Results indicated that partners who drank more were also more distressed, as indicated by higher levels of anxiety, depression, and anger, even when controlling for their service member partner's drinking (Rodriguez et al., 2017). Furthermore, concerned partners who reported more heavy drinking of their own also reported being more likely to support their military partner's hazardous drinking and less likely to be supportive of their military partner's sobriety (Rodriguez et al., 2017).

Collectively, this research supports the notion that spouses of service members and veterans can also experience distress related to their partner's military experiences which may contribute to hazardous drinking and associated patterns of alcohol consumption. Consequently, research is needed that considers psychological distress and alcohol use dyadically, including perspectives from both the veteran and spouse/partner. Our purpose is to address these shortcomings within the literature by modeling the mutual influence or intricate interplay of psychological distress and drinking behaviors which occurs between veterans and their spouse/partners. Our approach also enabled us to explore the direct and indirect pathways between each person's psychological distress, hazardous drinking index denoting level of potential risk for problem development, and patterns of alcohol consumption in the couples' daily lives.

\section{Present Study}

The present study aims to investigate drinking behaviors in a dyadic context in a sample of post-9/11 veterans and their partners. Whereas the previous-reviewed literature has examined drinking behaviors in military samples, there is a dearth of studies focused on veterans and 
matched samples of military-connected couples, which is important as both members of military couples may be at higher risk of hazardous drinking behavior compared to their civilian counterparts (Vest et al., 2018). Further, other work has failed to examine the dyadic effects of drinking in military couples, thus we will utilize Actor-Partner Interdependence Models (APIM) to estimate how veterans and their spouses influence themselves and one another (Kenny \& Cook, 1999). The model provides estimates of both actor effects, or the extent to which one's own predictor relates to one's own outcome, as well as partner effects, or the extent to which one's predictor relates to the partner's outcome, controlling for actor effects.

This work also aims to improve upon previous work by including drinking measures collected as it occurred in a daily diary study, as opposed to retrospective reports of drinking, which bolsters the validity of drinking reports (Perrine, Mundt, Searles, \& Lester, 1995). Given that many studies of alcohol consumption assess drinking patterns over the course of a month (e.g., see Dufour, 1999), our approach to gauge alcohol quantity and drinking frequency patterns by aggregating over 32 daily reports is an appropriate and indeed valid method for examining our research questions. In particular, daily drinking reports have been shown to be more valid then typical retrospective reports (Dufour, 1999), and show high correspondence to blood alcohol tests (e.g., Perrine, Mundt, Searles, \& Lester, 1995).

We hypothesized that the hazardous drinking index, which we measured with the AUDIT (Babor, Higgins-Biddle, Saunders, \& Monteiro, 2001), would be positively associated with the number of drinks per drinking day for veterans (Hypothesis 1A or H1A) and their spouses (Hypothesis 1B or H1B) (see Figure 1), or significant actor effects for the AUDIT-mean drinks per drinking day relationships. AUDIT scores would also predict the frequency of drinking days, revealed in significant actor effects for AUDIT-drinking frequency relationships $(\mathrm{H} 2 \mathrm{~A}$ and $\mathrm{H} 2 \mathrm{~B}$, 
for veterans and spouses, respectively) (see Figure 2). We also hypothesized that psychological distress would be associated with subsequent: hazardous drinking for veterans and spouses ( $\mathrm{H} 3 \mathrm{~A}$ \& H3B) (see Figure 3), drinking frequency (H4A \& H4B) (see Figure 4), and mean drinks per drinking day for both members of the couple (H5A \& H5B) (see Figure 5). Lastly, we hypothesized that indirect effects from psychological distress on subsequent drinking frequency for veterans and spouses (H6A \& H6B) and mean drinks per drinking day for veterans and spouses (H7A \& H7B) via hazardous drinking (the AUDIT). In each case, we predict the presence of significant actor effects for both veterans and spouses. Given the lack of evidence to guide directional hypotheses on partner effects, we investigated research questions regarding interdependence between veterans and spouses on alcohol use as well as their psychological distress, which would be indicated by the presence of significant partner effects.

[INSERT Figures 1-5]

\section{Method}

\section{Overview}

Participants were recruited through a larger study, a workplace study with veterans. The workplace study was designed to develop and scientifically evaluate supportive supervisor training with goals of increasing employment retention of veterans, augmenting workplace culture, and promoting overall well-being of veterans and their families. Veterans and their partners were recruited through 35 workplace organizations throughout the state of Oregon. In order to be eligible for the study, veterans must have worked at least 20 hours per week and served in the armed forces since 2001. The current sample included post-9/11 separated active duty as well as a small representation of U.S. Army Reserves and National Guardsman (18\%) who worked primarily in the civilian sector, together referred to as veterans for simplicity. After 
passing an eligibility screener, veterans provided consent and received an electronic link to a baseline survey. One week after veterans completed their surveys, they were given the opportunity to enroll in the daily diary component of the veteran workplace study, a 32-day daily diary survey with their spouses. The daily diary component comprised a sub-study of the veteran workplace study, which aimed to investigate the day-to-day issues pertaining to veterans and their families (Arpin et al., 2018), and provided the daily drinking reports that are the focus of the present study. To be eligible for the daily diary sub-study, couples were required to be either married or cohabiting for at least 6 months; given that the majority of couples were married (89.6\%), we refer to partners as spouses for simplicity. Additional details about veteran workplace study can be found in Hammer and colleagues (2017).

\section{Participants}

In all, 509 veterans completed the SERVe baseline survey, of which 395 veterans were eligible for participation and sent a recruitment email for the couples' sub-study. Baseline surveys were completed by 260 spouses with enrolled veteran partners. Of the 260 veteranspouse couples who completed the baseline survey, 191 veterans and 188 spouses enrolled (173 matched couples or $66.5 \%$ of eligible couples) in the 32-day diary study and provided at least 1 day of daily data reports, from which the alcohol quantity and frequency outcome measures were derived. However, data from an additional 11 couples was not included in the current study analysis sample because those couples completed a pilot version of the daily survey that did not include present study variables, resulting in a matched daily sample of 162 couples. Of note, the diary study participants (veterans) were not significantly different from the larger study sample on any of our baseline study variables. 
Thus, our matched veteran and spouse baseline sample included 520 participants or 260 matched couples, comprised of mostly male veterans $(88.5 \%)$ who on average were 38.4 years of age $(\mathrm{SD}=9.1)$. Veteran spouses were mostly female $(89.1 \%)$ who on average were 36.6 years of age $(\mathrm{SD}=9.06)$. Veterans and spouses were mostly White $(83.3 \% \& 79.7 \%)$. The average relationship length for veterans and spouses was 11.9 years $(\mathrm{SD}=8.45)$. The majority of couples were also parents $(80.4 \%)$ who on average had approximately two children $(\mathrm{M}=1.89, \mathrm{SD}=1.15)$ living in the home $3+$ days per week. In terms of military demographics, our veteran sample was primarily comprised of individuals who held enlisted ranks $(81.2 \%)$. The majority of our sample also had deployment experiences with an average of 18.35 total months of deployment $(\mathrm{SD}=$ 16.26) throughout their military tenure. Participants were compensated $\$ 25$ for their baseline survey completion with an option to enroll in the 32-day daily diary sub-study that started one week later, for further compensation (up to \$90). The study protocol was approved by Institutional Review Boards at Oregon Health \& Science University and Portland State University.

\section{Measures and procedure}

Participants were instructed to complete the veteran workplace study baseline survey, which asked questions about health, occupational, and family characteristics. The Internet survey data was collected through Qualtrics@2013 (Provo, UT) and took approximately 50 minutes to complete. Approximately one week later, veterans and their spouses began the Internet daily diary sub-study, in which they completed daily online surveys between the hours of 5-11 PM for regular shift workers and between 5-11 AM for night shift workers over the course of 32 days. The daily surveys (5-10 min.) inquired about health, well-being, as well as occupational and 
relationship functioning throughout the course of 32-days. The alcohol-related questions in the daily diary sub-study were asked approximately halfway through the survey.

The daily diary sub-study compliance rate was calculated for couples, in which $77.87 \%$ of possible surveys were completed, which is comparable to other daily diary studies (e.g., Green et al., 2006; Mohr et al., 2005). We developed the brief daily diary reports to ensure the survey was minimally intrusive and fatiguing based on published guidelines (e.g., Mohr et al., 2001; Reis \& Gable, 2000). For example, we employed easy-to-complete checklists and consistent response options across similar items. Of note, an inspection of missing data in the Internet survey and daily diary revealed no patterns consistent with study fatigue or systematic bias.

Alcohol Use Disorders Identification Test (AUDIT). The 10-item AUDIT (Babor et al., 2001) was used to assess hazardous alcohol consumption and completed during the baseline survey. The AUDIT gauges alcohol quantity and frequency of consumption, drinking behaviors, as well as alcohol related problems and is the current gold standard for measuring alcohol misuse. Questions include: How often do you have a drink containing alcohol? How often do you feel guilt or remorse after drinking? Responses are scored on a weighted scale between 0 and 4 with higher scores indicating higher levels of severity. Scores were summed yielding a range between 0 -40. Internal consistency was $\alpha=.79$ for veterans and $\alpha=.74$ for spouses.

Psychological Distress. An adapted version of the 6-item K6 (Kessler et al., 2003) was used to gauge levels of psychological distress and was also completed during the baseline survey. The measure has been validated and used to distinguish between various levels of mental illness. We used a 4-point Likert scale $(1=$ none of the time, $4=$ most of the time $)$ scale which inquired about emotional experiences over the past 30 days and include questions such as: How often have you felt hopeless? How often have you felt restless or fidgety? The six items were 
summed and yielded a range between 1 and 24. Internal consistency for the sample was $\alpha=.89$ for veterans and $\alpha=.87$ for spouses.

DAILY DIARY SUBSTUDY: Alcohol Use Reports. Veteran and spouse drinking quantity and frequency variables were aggregated from the daily diary sub-study daily reports (Sobell \& Sobell, 1995). Throughout the sub-study, 5- to 10-minute electronic surveys were sent out daily and participants were instructed to complete their surveys after work between the hours of 5PM and 11PM. During each login, participants reported on the number of drinks consumed on the previous day from 5PM-11PM, the current day between 12AM-7AM, and the current day between 8AM-5PM. It is important to note that the daily study provided a graphic display on the survey webpage, which explicitly defined one standard drink as 1 12-oz. beer, 1 8-9 oz. malt liquor, $15-\mathrm{oz}$ wine, and $1.5 \mathrm{oz}$. distilled spirits; (International Center for Alcohol Policies, 1988), based on criteria from the National Institute of Alcohol Abuse and Alcoholism (NIAAA, n.d.), which was created to standardize alcohol consumption measures across studies and populations, enhancing accuracy of reports (Dufour, 1999). Evidence to date suggests that there are no gender differences in under-reporting when completing alcohol surveys (Livingston \& Callinan, 2015) which mitigates concerns when measuring number of drinks reported by men and women. Mean drinks per drinking day (DDD) were calculated across the 32-day period for veterans and spouses. Drinking frequency (FREQ) was estimated by calculating the percentage of reporting days on which veterans and spouses consumed alcohol.

\section{Data Analysis}

A series of Actor-Partner Interdependence Models or APIMs (Kenny \& Cook, 1999) were conducted to assess the interdependence between members of military-connected couples on various dimensions of drinking-related behaviors as well as psychological distress. These 
models were conducted with structural equation modeling (Mplus Version 5.1; Muthén \& Muthén, 2008). Military status, veteran vs. spouse, was used as a distinguishing variable in APIM models (Kenny \& Cook, 1999) to denote the role of each member of the dyad in statistical analyses. Each of the paths were assessed for distinguishability so that models could be simplified as appropriate; in other words, whether the veteran and spouse partner paths were different or similar to one another. Paths that were found to be indistinguishable and constrained to be equal between veterans and spouses were AUDIT-FREQ and DISTRESS-FREQ. Given that the inclusion of covariates warrant caution in dyadic data analyses (Kenny, Kashy, \& Cook, 2006), we did not adjust for covariates in our models. However, potential variables such as gender, age, relationship factors, or military variables were not significantly associated with the drinking variables derived from daily diary assessments. Finally, we examined the potential for nonindependence due to military status (i.e., separated active duty vs. active duty guard/reserves) via intraclass correlation coefficients; obtained results for drinking variables of interest were exactly zero. Using a conservative cutoff of .10 (Hox, 2002), our results suggest that outcomes were not dependent on military status.

\section{Results}

\section{Descriptive Statistics}

Baseline assessments of hazardous drinking indicated that the average AUDIT score for veterans was $4.56(\mathrm{SD}=4.60)$. Spouses had an average AUDIT score of $2.80(\mathrm{SD}=3.59)$. The dyadic sample was also comprised of non-drinkers. Results indicated that $14.7 \%$ of our veteran sample were non-drinkers and $25.8 \%$ of the spouses were non-drinkers. These abstainers were included in all of our analyses. Daily data from the daily diary sub-study were then analyzed to determine the average amount of drinks consumed on drinking days among veterans and 
spouses. We computed aggregated drinking values based on all available values and findings indicated that participant response rates across observation days were stable. On drinking days, veterans on average consumed 2.23 drinks $(\mathrm{SD}=1.26)$, whereas spouses on average consumed 1.81 drinks $(\mathrm{SD}=.91)$. Drinking frequency was also assessed over the course of 32 days and indicated that veterans on average consumed alcohol on $33.69 \%$ of their reported days $(\mathrm{SD}=$ $32.41 \%)$, while spouses consumed alcohol on $24.86 \%$ of their reporting days $(\mathrm{SD}=30.85 \%)$. Not surprisingly, responses displayed a higher variance for drinks consumed during the 5PM11PM timeframe in comparison to other time windows which could suggest that participants were completing their daily surveys with accuracy. Similar to other studies of daily drinking reports, drinking was most common on weekends and least common on Tuesdays; number of drinks per drinking day varied from $\mathrm{M}=2.30(\mathrm{SD}=1.60)$ on Tuesdays to $\mathrm{M}=3.19(\mathrm{SD}=2.58)$ on Sundays (i.e., capturing Saturday night drinking). Finally, findings indicated that the average level of veteran emotional distress was $1.79(\mathrm{SD}=.71)$, while spouses reported an average level of $1.62(\mathrm{SD}=.63)$ on the K-6 emotional distress scale (see Tables 1 and 2$)$.

[Insert Table 1 and 2 here]

\section{Actor-Partner Interdependence Models}

Hazardous drinking and dimensions of alcohol use. Two models were conducted to determine the extent to which hazardous drinking related to particular dimensions of alcohol use. In the first model, AUDIT was positively associated with DDD for veterans $(b=.20, p<.001)$ and for spouses $(b=.13, p<.001)$, indicating that hazardous drinking behaviors were associated with subsequent higher average drinks per drinking day, consistent with Hypotheses 1A and 1B. Additionally, a partner effect emerged such that veteran AUDIT scores were positively 
associated with spouse DDD, indicating that spouses consumed more drinks per drinking day when their veteran partners had higher hazardous drinking scores $(b=.04, p<.05)$.

In the second model, AUDIT was positively associated with FREQ for both members of the couple $(\mathrm{b}=4.20, \mathrm{p}<.001)$, indicating that hazardous drinking behavior was associated with subsequent higher frequency of drinking days within person, thereby supporting Hypotheses $\mathrm{H} 2 \mathrm{~A}$ and $\mathrm{H} 2 \mathrm{~B}$. This model also revealed partner effects such that FREQ was positively associated with partner's AUDIT scores for both members of the couple $(b=.75, p<.05)$, indicating that both members of a couple drank more frequently when their respective partner had higher hazardous drinking scores. The presence of partner effects provided support for research questions about the interdependence of alcohol use in military couples.

Psychological distress and drinking. Five models were conducted to assess the relationships at baseline between psychological distress and AUDIT, FREQ and DDD. In support of Hypotheses H3A and H3B, psychological distress was positively related to AUDIT scores for veterans $(\mathrm{b}=1.84, \mathrm{p}<.001)$ and for spouses $(\mathrm{b}=1.08, \mathrm{p}<.01)$, indicating that feeling distressed was associated with subsequent higher hazardous drinking behaviors. Note that an equally plausible model featuring the reverse direction of these variables was tested and was significant but the magnitude of the associations was much smaller such that AUDIT scores were positively associated with subsequent psychological distress but to a lesser extent for veterans $(\mathrm{b}$ $=.05, \mathrm{p}<.001)$ and for spouses $(\mathrm{b}=.03, \mathrm{p}<.01)$. Psychological distress was also associated with subsequent frequency of drinking days for both members of the couple $(b=5.52, p<.05)$, supporting Hypotheses H4A and H4B. Contrary to Hypotheses H5A and H5B, psychological distress was not found to be associated with DDD for either partner. No partner effects emerged 
for any of these models, such that we found no evidence that one partner's distress predicted the other's drinking outcomes.

The final model conducted was a mediated Actor-Partner Interdependence Model (APIMeM) that was conducted to assess the indirect pathways from psychological distress at baseline and the outcomes of FREQ and DDD via the hazardous drinking (the AUDIT), utilizing 5,000 bootstrapped resamples. The total indirect effect from psychological distress to FREQ through the AUDIT was $(b=6.86, \mathrm{SE}=2.15,95 \% \mathrm{CI}[2.99,11.42], \mathrm{p}<.001)$ for veterans and $(b=5.59, \mathrm{SE}=2.43,95 \% \mathrm{CI}[1.02,10.56], \mathrm{p}<.05)$ for spouses, supporting hypotheses H6A \& H6B, respectively. The total indirect effect from psychological distress to DDD through the AUDIT was $(b=0.39, \mathrm{SE}=0.11,95 \% \mathrm{CI}[0.20,0.66], \mathrm{p}<.001)$ for veterans and $(\mathrm{b}=0.16, \mathrm{SE}$ $=.07595 \%$ CI $[0.03,0.33], \mathrm{p}<.05)$ for spouses, supporting hypotheses H7A \& H7B. See Figure 6 for specific path estimates. Additionally, note that no direct effects or partner effects emerged. [Insert Figure 6 here]

\section{Discussion}

The current study aimed to examine drinking behaviors among veterans and their spouses using a dyadic approach. Few studies have examined the drinking behaviors of military spouses or veterans from non-clinical samples. The findings of Vest and colleagues (2018) were among the first to suggest that separated, male service members may be at heightened risk for alcohol problems compared to male, active duty (AD) service members. Whereas, the vast majority of Vest et al.'s (2018) sample were made up of service members in an AD component, our sample was complementary to their sample and was primarily comprised of separated AD service members. Our findings indicate partner drinking effects, wherein veterans’ AUDIT scores predicting their spouses' average drinking volume on drinking days (DDD), whereas partner 
effects were evident for AUDIT scores predicting drinking frequency for both partners. Further investigation of indirect actor effects (APIMeM) revealed that hazardous drinking as measured by the AUDIT, was a mechanism through which psychological distress was associated with an individual's average drinking volume on drinking days, as well as their drinking frequency. In other words, psychological distress related to greater number of drinks and drinking more frequently through one's status as a hazardous drinker.

One aim of the present study was to investigate the rates of hazardous drinking in a veteran sample, as much of the previous work investigating hazardous drinking in military samples has focused on AD samples (e.g. Bray et al., 2006). In our sample of high-functioning employed veterans, we found that $23 \%$ of our veteran sample met criteria for hazardous drinking. Previous work investigating civilian levels of heavy drinking found that $10.8 \%$ of primary care patients across multiple sites, met the criteria for hazardous drinking (Gordon et al., 2001). Additionally, previous work examining rates of hazardous alcohol use in National Guard members found $29.2 \%$ of service members met criteria for hazardous alcohol use (Blow et al., 2013). Our rates are in line with, if not a bit lower, than what Blow and colleagues reported. It is possible that after separation veterans may reduce their heavy drinking slightly, however it is clear that military-connected individuals have substantially higher rates of hazardous drinking than their civilian counterparts (23\% vs. $10.8 \%)$. In contrast, our estimates of hazardous drinking for military spouses are consistent with levels reported among civilians, though the levels reported here have not been adjusted for gender and research has documented the potential need for a lower threshold for women (Neumann et al., 2004), which suggests our estimate of hazardous drinkers among spouses (who are mostly women) is too conservative. The present study also has important implications for our greater understanding of the hazardous drinking 
behaviors of employed veterans and their spouses. With very little previous work investigating military spouses' drinking behaviors, the results of the present study shed light on the dyadic context of drinking in an understudied population. Whereas previous research on service members has found high rates of hazardous drinking, it is clear that the effects of this go beyond one's own drinking behavior, and spillover to one's partner. We found that veteran hazardous drinking was related to their spouse's DDD. From this result, we can infer that when the veteran partner is engaging in more hazardous drinking, their spouses are far more likely to be drinking more on those occasions when they drink. However, it is important to note that spouse hazardous drinking was not significantly related to veteran drinks per drinking day, which implies there may be influences on drinking behavior that are driven more strongly by the veteran, which is plausible as they are more likely to engage in hazardous drinking behavior than their spouses. Alternatively, when looking at hazardous drinking predicting frequency of drinks in a dyadic model, it was found that both partners influenced their spouse's drinking frequency. It appears that hazardous drinking partners influence how often each other drinks, which combined with the other partner effect reveals a troubling pattern wherein a hazardous drinking veteran can influence his or her spouse to not only drink more often, but to also drink more alcohol when they do drink, which is likely to lead to subsequent alcohol-related problems.

Consistent with previous research (Bryant \& Kim, 2013; Choi \& DiNitto, 2011a; Choi \& NiNitto, 2011b), we found associations between distress and drinking behavior, including AUDIT scores, frequency, and drinks per drinking day. Our mediational analysis also revealed that distress was associated with one's own alcohol use, which in turn, predicted greater alcohol use in their spouses. However, we did not find any significant partner effects between one person's psychological distress and the partner's drinking. 
Additionally, gender represents one potential challenge in our study in that our sample is made up of predominantly male veterans and predominantly female spouses, because gender and our distinguishing variable (veterans vs. spouses) are confounded. While this may be similar to the breakdown of veterans in the U.S. (Department of Defense, 2018), it is still important to consider the effects of gender in the relational drinking context. We know that hazardous drinking rates vary by gender in veteran samples as males have been found to have higher rates $(30.2 \%)$ than females $(16.3 \%$; Scott et al., 2013); thus, it is a limitation of the present study. It is also important for future work to consider the drinking behavior of same-sex veteran couples, as none were present in this sample. Another methodological limitation of the present study is the use of self-report measures. It is possible that as our participants were recalling their drinks consumed, they may not be remembering correctly, or may be incorrectly counting their drinks. Previous work has found that people tend to underestimate the amount of alcohol they have consumed with self-report measures (Stockwell et al., 2004). However, use of a daily diary design should mitigate many potential errors, by allowing for shorter periods between drinking and recall; methods that have been shown to correspond to blood alcohol reports (Perrine et al., 1995). While our use of a daily diary survey could elicit concerns of survey fatigue, the brevity of the daily survey (5-10 min.) coupled with the fact that patterns of response were relatively stable across the 32 days reduces such concerns.

Other limitations regarding generalizability of our sample include the limited racial diversity of our sample. Veterans in our sample were $83.3 \%$ White and their spouses were $79.7 \%$ White. This is less diverse than the U.S. veteran population (Department of Defense, 2018), and while it may approximately reflect the demographics of veterans, there may be unique experiences of minority veterans that could have the potential to influence their drinking 
behavior. Additionally, much of the literature on veteran drinking relies on samples recruited from the VA. The veterans included in the present sample were all working at least 20 hours per week and most were married or living with their partner. Thus, our findings may be more indicative of the drinking behaviors of higher functioning veterans as only $48 \%$ of veterans utilize VA services (Department of Veterans Affairs, 2017) and it is possible that our findings may vary from a sample recruited exclusively from the VA. It is also important to note that the veterans in our sample had been separated from the military on average for six years and that there are specific challenges associated with the transition period that may affect hazardous drinking differently than later points in the transition that may be less stressful. Future studies should investigate veteran couples at various points in their transition from active duty service, as well as at various time points of a service-member's career, to see how their drinking behaviors may change. These approaches may provide further insight in developing solutions aimed at reducing hazardous drinking in military-connected couples while promoting healthy behaviors that better support the military family.

In sum, our study indicates that many high-functioning veterans still engage in hazardous alcohol use years after separation which also affects the drinking volume and frequency of their spouses. Our findings may serve to inform the DoD and the VA by calling attention to the interdependent nature of drinking behaviors that occur between military-connected dyads while shedding light on the association between distress and hazardous drinking. It would behoove providers and researchers to inquire about the drinking behaviors of military-connected spouses to gain insight into the factors that influence drinking behaviors of veterans, service members, and their families. Such practices could lead to improvements in the development of effective treatment options and interventions while improving the wellbeing of families who have served. 


\section{References}

Arpin, S. N., Starkey, A. R., Mohr, C. D., Greenhalgh, A. M. D., \& Hammer, L. B. (2018). “A well spent day brings happy sleep": A dyadic study of capitalization support in militaryconnected couples. Journal of Family Psychology, 32(7), 975-985.

Babor, T. F., Higgins-Biddle, J. C., Saunders, J. B., \& Monteiro, M. G. (2001). AUDIT: The Alcohol Use Disorders Identification Test. Geneva, Switzerland: World Health Organization.

Bartel, S. J., Sherry, S. B., Molnar, D. S., Mushquash, A. R., Leonard, K. E., Flett, G. L., \& Stewart, S. H. (2017). Do romantic partners influence each other's heavy episodic drinking? Support for the partner influence hypothesis in a three-year longitudinal study. Addictive Behaviors, 69, 55-58. https://doi.org/10.1016/j.addbeh.2017.01.020

Blow, A. J., Gorman, L., Ganoczy, D., Kees, M., Kashy, D. A., Valenstein, M., ... Chermack, S. (2013). Hazardous drinking and family functioning in National Guard veterans and spouses post deployment. Journal of Family Psychology, 27(2), 303-313.

Booth, B., Segal, M. W., Bell, D. B., Martin, J. A., Ender, M. G., Rohall, D., et al. (2007). What we know about army families: 2007 update. Fairfax, VA: Caliber.

Bray, R. M., Pemberton, M. R., Hourani, L. L., Witt, M., Olmsted, K. L., Brown, J. M., ... \& Scheffler, S. (2009). Department of Defense survey of health related behaviors among active duty military personnel (No. RTI/10940-FR). RESEARCH TRIANGLE INST (RTI) RESEARCH TRIANGLE PARK NC.

Bryant, A. N., \& Kim, G. (2013). The relation between frequency of binge drinking and psychological distress among older adult drinkers. Journal of Aging and Health, 25(7), 1243-1257. https://doi.org/10.1177/0898264313499933 
Castro, C. A., \& Kintzle, S. (2014). Suicides in the military: the post-modern combat veteran and the Hemingway effect. Current Psychiatry Reports, 16(8), 460.

Center for Behavioral Health Statistics and Quality. (2016). Key substance use and mental health indicators in the United States: Results from the 2015 National Survey on Drug Use and Health (HHS Publication No. SMA 16-4984, NSDUH Series H-51). Retrieved from http://www.samhsa.gov/data/

Choi, N. G., \& DiNitto, D. M. (2011a). Drinking, smoking, and psychological distress in middle and late Life. Aging and Mental Health, 15(6), 720-731. https://doi.org/10.1080/13607863.2010.551343

Choi, N. G., \& Dinitto, D. M. (2011b). Psychological distress, binge/heavy drinking, and gender differences among older adults. American Journal on Addictions, 20(5), 420-428.

Cooper, M. L., Russell, M., Skinner, J. B., \& Windle, M. (1992). Development and validation of a three-dimensional measure of drinking motives. Psychological assessment, 4(2), 123.

Department of Defense (2018). 2017 Demographics Profile of the Military. Retrieved from https://www.icf.com/work/government/human-capital

Department of Veterans Affairs (2017). VA Utilization Profile FY 2016. Retrieved from https://www.va.gov/vetdata/docs/Quickfacts/VA_Utilization_Profile.pdf

Dufour, M. C. (1999). What is moderate drinking?: Defining “drinks" and drinking levels. Alcohol Research \& Health, 23(1), 5.

Foulstone, A. R., Kelly, A. B., Kifle, T., \& Baxter, J. (2016). Heavy alcohol use in the couple context: A nationally representative longitudinal study. Substance use \& misuse, 51(11), $1441-1450$. 
Fulton, J. J., Calhoun, P. S., Wagner, H. R., Schry, A. R., Hair, L. P., Feeling, N., .. Beckham, J. C. (2015). The prevalence of posttraumatic stress disorder in Operation Enduring Freedom Operation Iraqi Freedom (OEFOIF) Vet. Journal of Anxiety Disorders, 98-107.

Gorman, L. A., Blow, A. J., Ames, B. D., \& Reed, P. L. (2011). National Guard families after combat: Mental health, use of mental health services, and perceived treatment barriers. Psychiatric Services, 62(1), 28-34.

Gordon, A. J., Maisto, S. A., McNeil, M., Kraemer, K. L., Conigliaro, R. L., Kelley, M. E., \& Conigliaro, J. (2001). Three questions can detect hazardous drinkers. Journal of Family Practice, 50(4), 313-313.

Green, A. S., Rafaeli, E., Bolger, N., Shrout, P. E., \& Reis, H. T. (2006). Paper or plastic? Data equivalence in paper and electronic diaries. Psychological methods, 11(1), 87-105.

Gribble, R., Thandi, G. K., Goodwin, L., \& Fear, N. T. (2018). Hazardous alcohol consumption among spouses or partners of military service personnel: a systematic review of the literature. Journal of the Royal Army Medical Corps, 164(5), 380-388.

Hammer, L. B., Wan, W. H., Brockwood, K. J., Mohr, C. D., \& Carlson, K. F. (2017). Military, work, and health characteristics of separated and active service members from the Study for Employment Retention of Veterans (SERVe). Military Psychology, 29(6), 491-512.

Hawkins, S. A., Condon, A., Hawkins, J. N., Liu, K., Melendrez Ramirez, Y., Nihill, M. M., \& Tolins, J. (2018). What We Know about Military Family Readiness: Evidence from 20072017. Office of the Deputy Under Secretary of the Army Monterey, CA United States.

Homish, G. G., \& Leonard, K. E. (2007). The drinking partnership and marital satisfaction: The longitudinal influence of discrepant drinking. Journal of Consulting and Clinical Psychology, 75(1), 43-51. 
Hoopsick, R. A., Fillo, J., Vest, B. M., Homish, D. L., \& Homish, G. G. (2017). Substance use and dependence among current reserve and former military members: Cross-sectional findings from the National Survey on Drug Use and Health, 2010-2014. Journal of Addictive Diseases, 36(4), 243-251. https://doi.org/10.1080/10550887.2017.1366735

Hox, J. (2002). Quantitative methodology series. Multilevel analysis techniques and applications. Mahwah, NJ, US: Lawrence Erlbaum Associates Publishers.

International Center for Alcohol Policies (ICAP). (1998). What is a standard drink? (ICAP Report 5). Washington DC: Author.

Jacobson, I. G., Ryan, M. A., Hooper, T. I., Smith, T. C., Amoroso, P. J., Boyko, E. J., ... \& Bell, N. S. (2008). Alcohol use and alcohol-related problems before and after military combat deployment. JAMA, 300(6), 663-675.

Jacobson, I. G., Williams, E. C., Seelig, A. D., Littman, A. J., Maynard, C. C., Bricker, J. B., Rull, R. P., Boyko, E. J, \& Millennium Cohort Study Team. (2020). Longitudinal investigation of military-specific factors associated with continued unhealthy alcohol use among a large US military cohort. Journal of Addiction Medicine, 14(4), e53-e63. https://doi.org/10.1097/ADM.0000000000000596

Kehayes, I. L. L., Mackinnon, S. P., Sherry, S. B., Leonard, K. E., \& Stewart, S. H. (2017). Similarity in romantic couples' drinking motivations and drinking behaviors. Substance Abuse, 38(4), 488-492. https://doi.org/10.1080/08897077.2017.1355869

Khantzian, E. J. (2003). The self-medication hypothesis revisited: The dually diagnosed patient. Primary Psychiatry, 10(9), 47-54.

Kenny, D. A., \& Cook, W. (1999). Partner effects in relationship research: Conceptual issues, analytic difficulties, and illustrations. Personal relationships, 6(4), 433-448. 
Kenny, D. A., Kashy, D. A., \& Cook, W. L. (2006). Dyadic data analysis. Guilford press.

Kessler, R. C., Barker, P. R., Colpe, L. J., Epstein, J. F., Gfroerer, J. C., Hiripi, E., . . Zaslavsky, A. M. (2003). Screening for serious mental illness in the general population. Archives of General Psychiatry, 60, 184-189. doi:10.1001/archpsyc.60.2.184

Lipari, R. N., Forsyth, B., Bose, J., Kroutil, L. A., \& Lane, M. E. (2016). Spouses and children of US military personnel: Substance use and mental health profile from the 2015 National Survey on Drug Use and Health. Substance Abuse and Mental Health Administration.

Livingston, M., \& Callinan, S. (2015). Underreporting in alcohol surveys: whose drinking is underestimated?. Journal of studies on alcohol and drugs, 76(1), 158-164.

Mohr, C.D., Armeli, S., Tennen, H., Carney, M., Affleck, G. \& Hromi, A. (2001). Daily interpersonal experiences, context and alcohol consumption: Crying in your beer and toasting good times. Journal of Personality and Social Psychology, 80(3), 489-500.

Mohr, C.D., Armeli, S., Tennen, H., Temple, M., Todd, M., Clark, J., \& Carney, M.A. (2005). Moving beyond the keg party: A daily process investigation of college student drinking motivations. Psychology of Addictive Behaviors, 19(4), 392-403.

Mohr, C. D., McCabe, C. T., Haverly, S. N., Hammer, L. B., \& Carlson, K. F. (2018). Drinking Motives and Alcohol Use: The SERVe Study of U.S. Current and Former Service Members. Journal of Studies on Alcohol and Drugs, 79(1), 79-87.

Mushquash, A. R., Stewart, S. H., Sherry, S. B., Mackinnon, S. P., Antony, M. M., \& Sherry, D. L. (2013). Heavy episodic drinking among dating partners: A longitudinal actor-partner interdependence model. Psychology of Addictive Behaviors, 27(1), 178-183. https://doi.org/10.1037/a0026653 
Muthén, L. K., \& Muthén, B. O. (2008). Mplus (Version 5.1) Muthen \& Muthen. Los Angeles, $C A$.

Neumann, T. , Neuner, B. , Gentilello, L. M., Weiss-Gerlach, E. , Mentz, H. , Rettig, J. S., Schröder, T. , Wauer, H. , Müller, C. , Schütz, M. , Mann, K. , Siebert, G. , Dettling, M. , Müller, J. M., Kox, W. J. and Spies, C. D. (2004), Gender Differences in the Performance of a Computerized Version of the Alcohol Use Disorders Identification Test in Subcritically Injured Patients Who Are Admitted to the Emergency Department. Alcoholism: Clinical and Experimental Research, 28: 1693-1701. doi:10.1097/01.ALC.0000145696.58084.08

National Institute on Alcohol Abuse and Alcoholism (NIAAA, n.d.). Retrieved from https://www.niaaa.nih.gov/what-standard-drink

Paul, L. A., Grubaugh, A. L., Frueh, B. C., Ellis, C., \& Egede, L. E. (2011). Associations between binge and heavy drinking and health behaviors in a nationally representative sample. Addictive Behaviors, 36(12), 1240-1245.

Perrine, M. W., Mundt, J. C., Searles, J. S., \& Lester, L. S. (1995). Validation of daily selfreported alcohol consumption using interactive voice response (IVR) technology. Journal of Studies on Alcohol, 56(5), 487-490.

Reis, H. T., \& Gable, S. L. (2000). Event-sampling and other methods for studying everyday experiences. In H.T. Reis, \&C.M. Judd (Eds.), Handbook of research methods in social and personality psychology (pp. 190-222). New York: Cambridge University Press.

Rodriguez, L. M., Osilla, K. C., Trail, T. E., Gore, K. L., \& Pedersen, E. R. (2017).

Alcohol Use among Concerned Partners of Heavy Drinking Service Members and Veterans. Journal of Marital and Family Therapy, 1-15. 
Scott, J. C., Pietrzak, R. H., Mattocks, K., Southwick, S. M., Brandt, C., \& Haskell, S. (2013). Gender differences in the correlates of hazardous drinking among Iraq and Afghanistan veterans. Drug and Alcohol Dependence, 127(1-3), 15-22. https://doi.org/10.1016/j.drugalcdep.2012.06.003

Seal, K. H., Bertenthal, D., Miner, C. R., Sen, S., \& Marmar, C. (2007). Bringing the War Back Home. Arch Intern Med, 167, 476-482. https://doi.org/10.1001/archinte.167.5.476

Sobell, L. C., \& Sobell, M. B. (1995). Alcohol consumption measures. Assessing alcohol problems: A guide for clinicians and researchers, 2, 75-99.

Stockwell, T., Donath, S., Cooper-Stanbury, M., Chikritzhs, T., Catalano, P., \& Mateo, C. (2004). Under-reporting of alcohol consumption in household surveys: a comparison of quantity-frequency, graduated-frequency and recent recall. Addiction, 99(8), 1024-1033.

Trone, D. W., Powell, T. M., Bauer, L. M., Seelig, A. D., Peterson, A. V., Littman, A. J., ... \& Boyko, E. J. (2018). Smoking and drinking behaviors of military spouses: Findings from the Millennium Cohort Family Study. Addictive behaviors, 77, 121-130.

Vest, B. M., Homish, D. L., Fillo, J., \& Homish, G. G. (2018). Military status and alcohol problems: Former soldiers may be at greater risk. Addictive Behaviors, 84(January), 139143. https://doi.org/10.1016/j.addbeh.2018.04.011

Vest, B. M., Heavey, S. C., Homish, D. L., \& Homish, G. G. (2018). Alcohol Misuse in Reserve Soldiers and their Partners: Cross-Spouse Effects of Deployment and Combat Exposure. Substance Use and Misuse, 53(5), 800-807. https://doi.org/10.1080/10826084.2017.1385632 
DFS demographics and military characteristics

\begin{tabular}{|c|c|c|}
\hline Demographic & $\%$ of Veterans & $\%$ of Spouses \\
\hline \multicolumn{3}{|l|}{ Gender } \\
\hline Male & 88.5 & 10.9 \\
\hline Female & 11.5 & 89.1 \\
\hline \multicolumn{3}{|l|}{ Race/ethnicity } \\
\hline American Indian/Alaskan Native & 1.6 & 0.8 \\
\hline Asian & 1.9 & 4.7 \\
\hline Black or African American & 0.8 & 0.8 \\
\hline Hawaiian Native or Pacific Islander & 0.4 & 0.4 \\
\hline White & 83.3 & 79.7 \\
\hline Hispanic & 0.8 & 0.8 \\
\hline Other & 0.4 & 0.4 \\
\hline Multiple & 10.9 & 12.5 \\
\hline \multicolumn{3}{|l|}{ Education } \\
\hline Less than high school & 0.0 & 1.2 \\
\hline High school diploma/GED & 5.4 & 7.0 \\
\hline Some college, no degree & 25.6 & 28.1 \\
\hline Completed college with degree/certificate & 48.5 & 46.9 \\
\hline Graduate study in progress or completed & 20.0 & 16.8 \\
\hline \multicolumn{3}{|l|}{ Current Military Status } \\
\hline Active (Guard/Reserves) & 20.8 & 1.2 \\
\hline Separated & 79.2 & 13.1 \\
\hline \multicolumn{3}{|l|}{ Military service type at separation } \\
\hline Regular Active Duty & 45.8 & -- \\
\hline National Guard/Reserve & 54.2 & -- \\
\hline \multicolumn{3}{|l|}{ Service branch } \\
\hline Army National Guard & 23.8 & -- \\
\hline Air National Guard & 6.9 & -- \\
\hline Army Reserves & 10.8 & -- \\
\hline Marine Reserves & 10.4 & -- \\
\hline Navy Reserves & 21.5 & -- \\
\hline Air Force Reserves & 5.4 & -- \\
\hline Coast Guard Reserves & 0.8 & -- \\
\hline Army & 12.3 & -- \\
\hline Navy & 0.0 & -- \\
\hline Air Force & 6.5 & -- \\
\hline Marine & 0.0 & -- \\
\hline Coast Guard & 1.5 & -- \\
\hline \multicolumn{3}{|l|}{ Rank/Pay Grade } \\
\hline Enlisted & 81.2 & -- \\
\hline
\end{tabular}


Officer

Has deployed

Never deployed

Deployed 1+ times

Dyad-level demographic

Military status

Active dual military (NGR)

Marital status

In a committed relationship (not cohabitating)

Cohabitating (but not married)

Married

Civil commitment or union

Parental status

At least one partner indicated children

Neither partner indicated children

Number of dependent children living in home

0

1

2

3

4 or more
18.8

12.3

87.7

$\%$ of dyads

0.8

1.2

8.8

89.6

0.4

80.4

19.6

10.7

26.5

37.2

18.4

7.1 


\section{Table 2}

Intercorrelation Matrix of Veteran and Spouse Study Variables

$\begin{array}{lllllllll}\text { Variable } & 1 & 2 & 3 & 4 & 5 & 6 & 7\end{array}$

1. Veteran AUDIT

2. Spouse AUDIT

$.313 * *$

3. Veteran DDD

$.656 * * .098$

4. Spouse DDD

$.344 * * \quad .594 * * \quad .287 * *$

5. Vet Frequency

$.525^{* *} \quad .310^{* *} \quad .264^{* *} \quad .167$

6. Spouse Frequency

$.233 * * \quad .567 * * \quad .066 \quad .242 * \quad .559 * *$

7. Veteran Distress

$.293 * * \quad .040 \quad .102 \quad .096 \quad .082 \quad .000$

8. Spouse Distress

$\begin{array}{lllllll}.094 & .192 * * & .018 & .119 & .208 * * & .185 * & .074\end{array}$

Note. $\mathrm{DDD}=$ Drinks per Drinking Day; $* p<.05, * * p<.01$ 
T1: Baseline SERVe

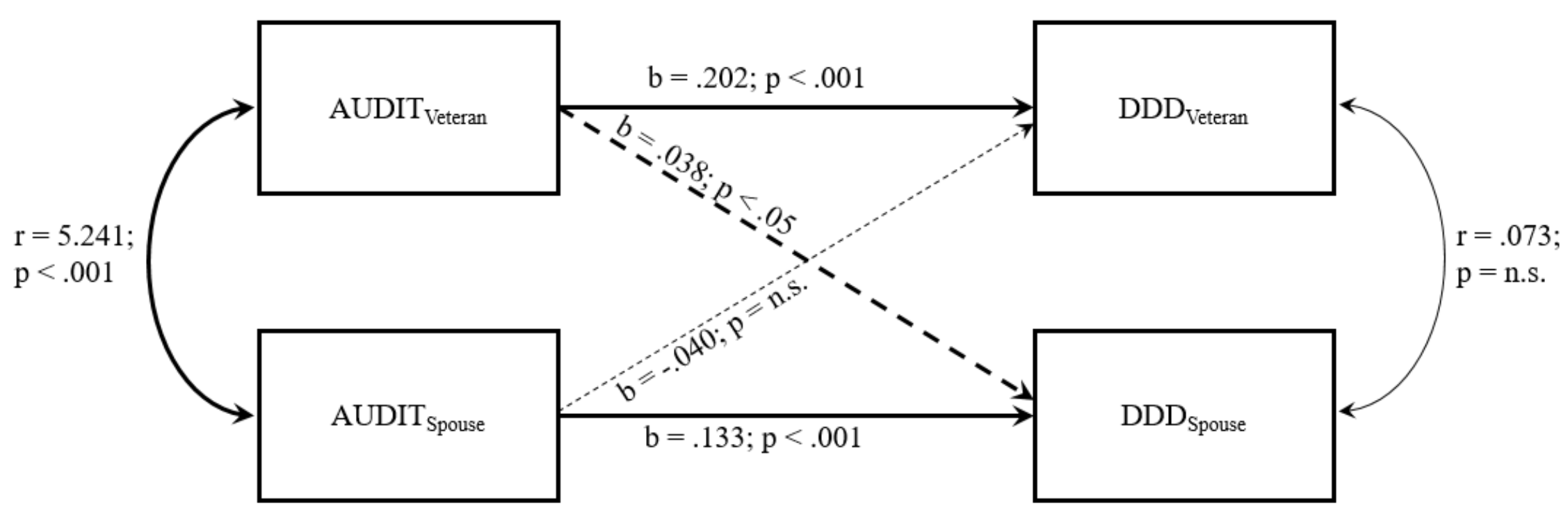

Figure 1. APIM depicting the effects of AUDIT at baseline on subsequent drinks on drinking days.

Hypothesis 1A: actor effect for AUDIT Veteran $_{\text {predicting } \text { DDD }_{\text {Veteran. Hypothesis }} \text { 1B: actor effect for AUDIT }}$ Spouse predicting DDD $_{\text {Spouse. }}$ Note. Actor effects are presented in solid lines while partner effects are presented in dashed lines. Significant paths are presented in thicker lines while nonsignificant paths are presented in thinner lines. 


\section{APIM of AUDIT and Drinking Frequency}

T1: Baseline SERVe

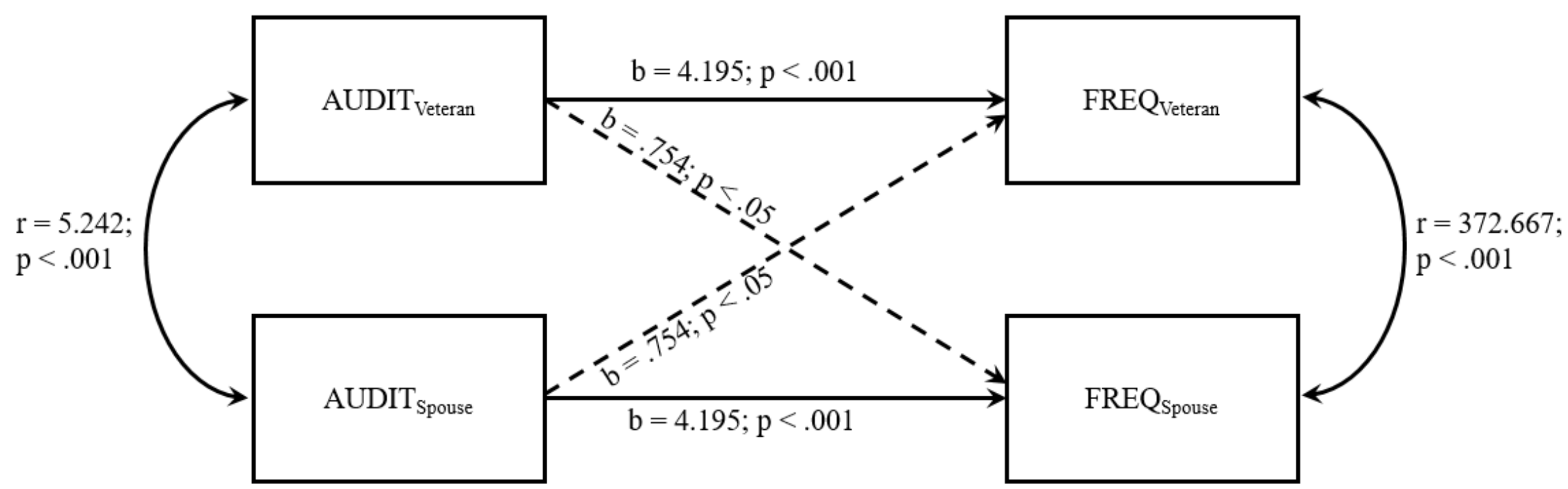

Figure 2. APIM depicting the effects of AUDIT at baseline on subsequent frequency of drinking days.

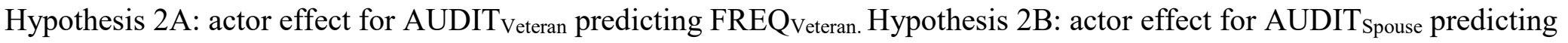
FREQ spouse.

Note. Actor effects are presented in solid lines while partner effects are presented in dashed lines. Significant paths are presented in thicker lines while nonsignificant paths are presented in thinner lines. 


\section{APIM of Psychological Distress and AUDIT}

T1: Baseline SERVe

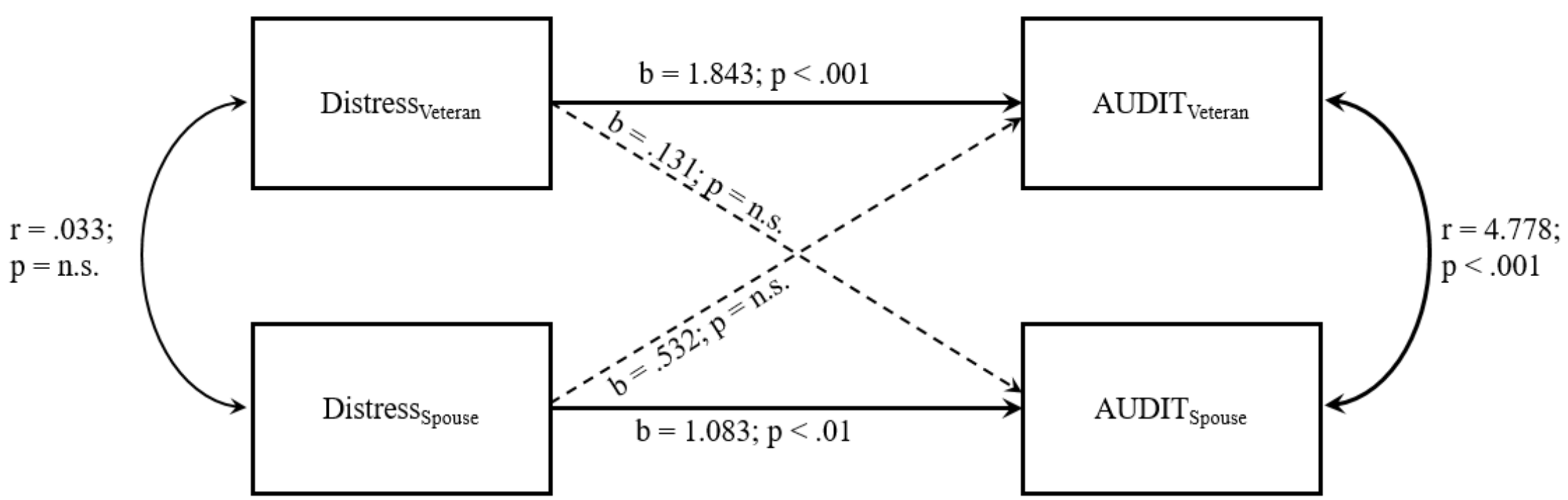

Figure 3. APIM depicting the effects of psychological distress at baseline on subsequent AUDIT.

Hypothesis 3A: actor effect for DISTRESS $V_{\text {Veteran }}$ predicting AUDITVeteran. Hypothesis 2B: actor effect for DISTRESS Spouse $_{\text {predicting }}$ AUDIT $_{\text {Spouse. }}$

Note. Actor effects are presented in solid lines while partner effects are presented in dashed lines. Significant paths are presented in thicker lines while nonsignificant paths are presented in thinner lines. 


\section{APIM of Psychological Distress and Drinking Frequency}

\section{T1: Baseline SERVe}

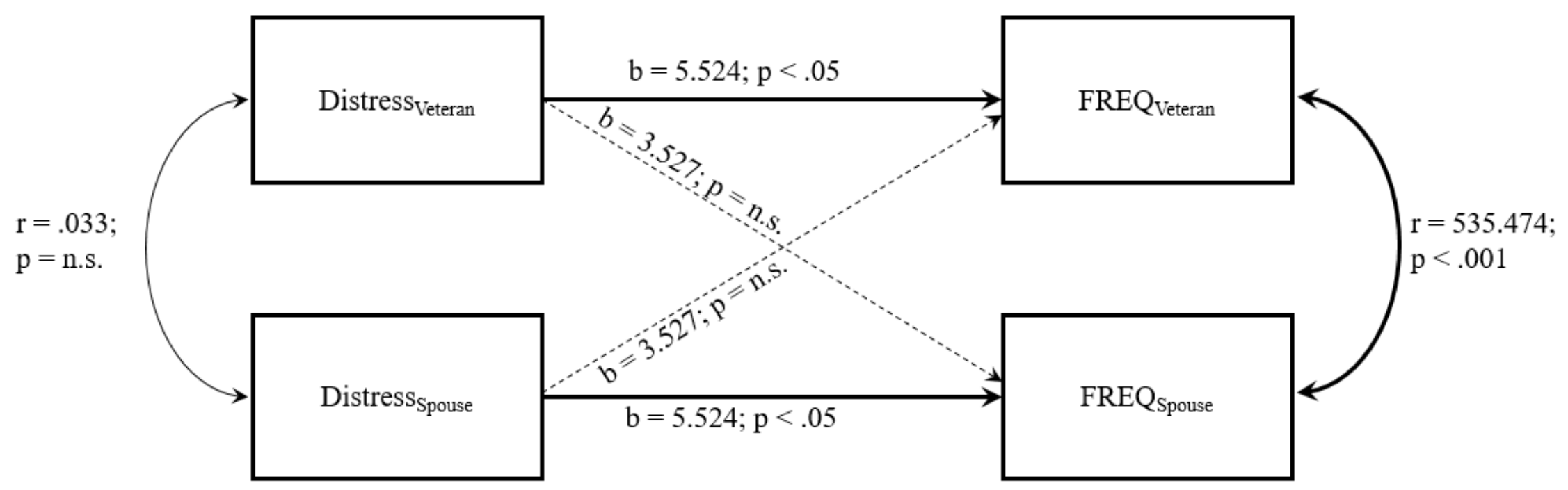

Figure 4. APIM depicting the effects of psychological distress at baseline on subsequent frequency of drinking days.

Hypothesis 4A: actor effect for DISTRESS Veteran predicting FREQVeteran. Hypothesis 4B: actor effect for DISTRESS FREQSpouse.

Note. Actor effects are presented in solid lines while partner effects are presented in dashed lines. Significant paths are presented in thicker lines while nonsignificant paths are presented in thinner lines. 


\section{APIM of Psychological Distress and Drinks per Drinking Day}

T1: Baseline SERVe

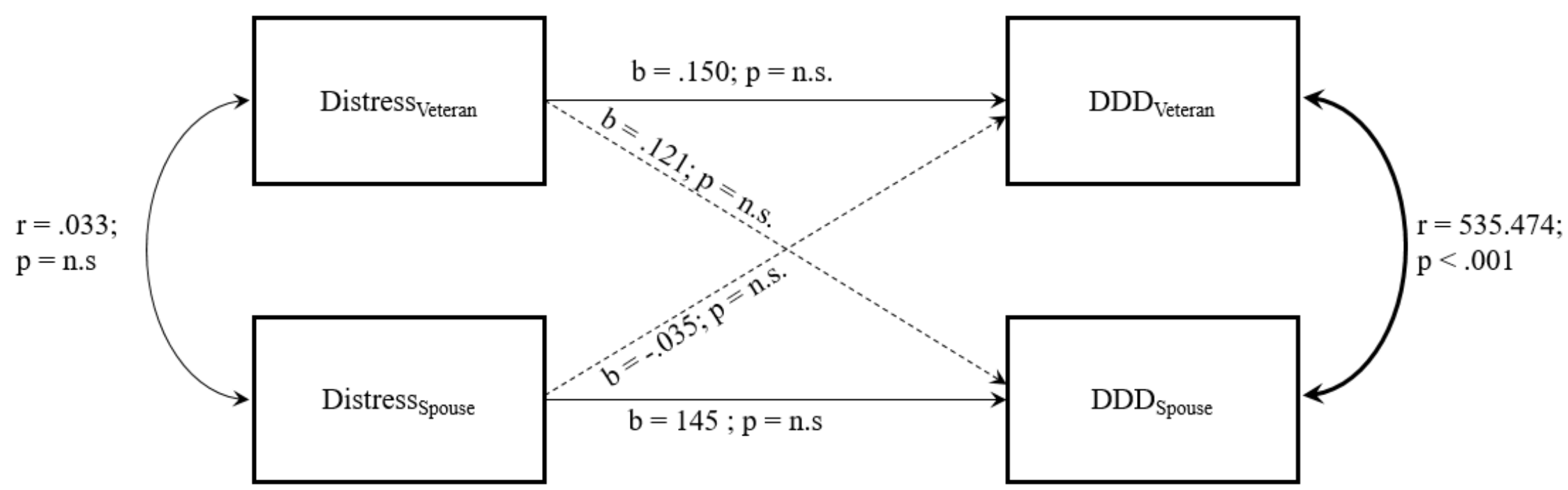

Figure 5. APIM depicting the effects of psychological distress at baseline on subsequent drinks on drinking days.

Hypothesis 5A: actor effect for DISTRESS ${ }_{\text {Veteran }}$ predicting DDD Veteran. Hypothesis 5B: actor effect for DISTRESS $_{\text {Spouse }}$ predicting DDD Spouse.

Note. Actor effects are presented in solid lines while partner effects are presented in dashed lines. Significant paths are presented in thicker lines while nonsignificant paths are presented in thinner lines. 
T1: Baseline SERVe

T1: Baseline SERVe

T2: Baseline DFS

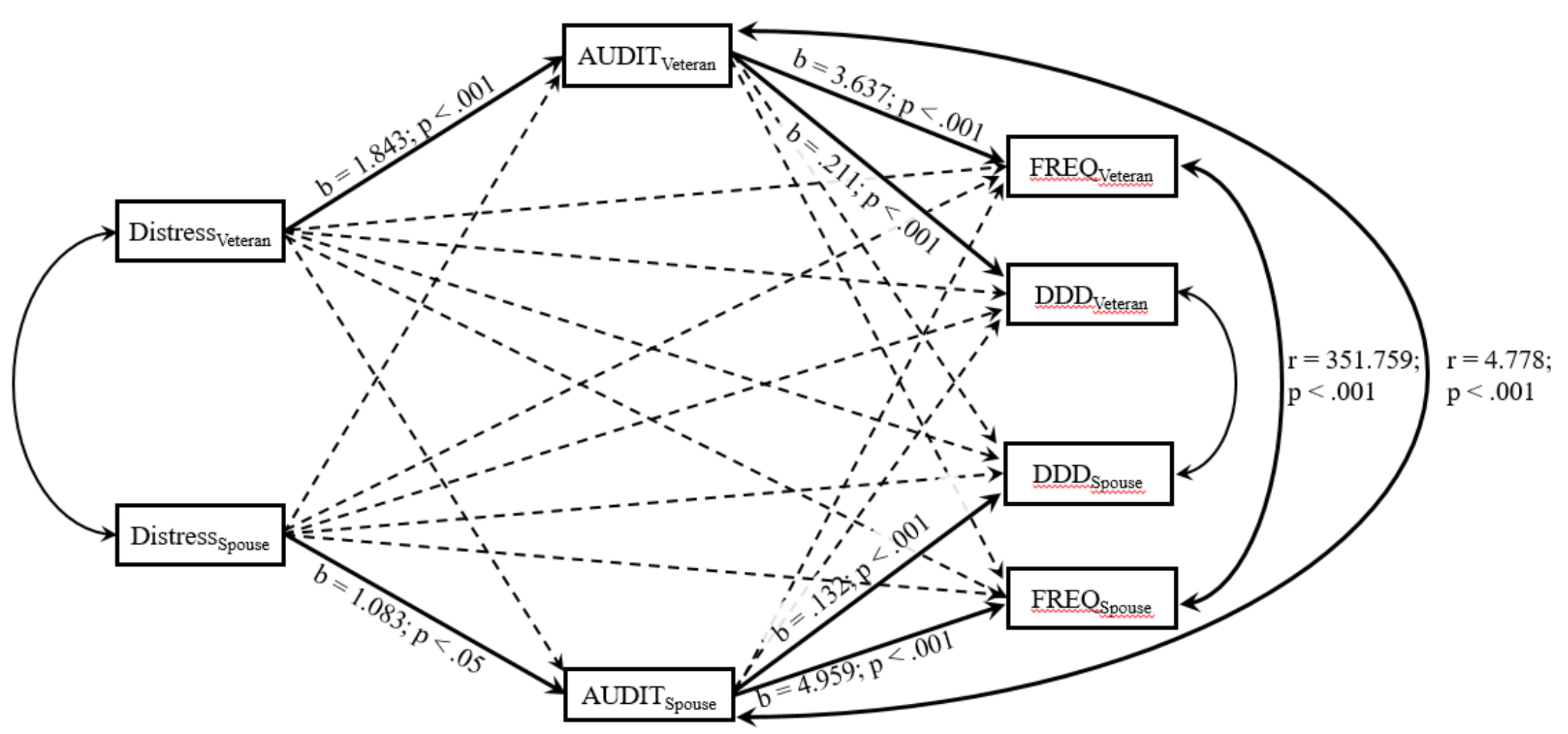

Figure 6. APIMeM depicting the effects of psychological distress at baseline on subsequent DDD FREQ through AUDIT.

Hypothesis 6A\&B: indirect effects from DISTRESS on FREQ through AUDIT for Veterans and Spouses. Hypothesis 7A\&B: indirect effects from DISTRESS on DDD through AUDIT for Veterans and Spouses.

Note. Actor effects are presented in solid lines while partner effects are presented in dashed lines. Significant paths are presented in thicker lines while nonsignificant paths are presented in thinner lines. 